\title{
Control of severe hemorrhage using C-clamp and arterial embolization in hemodynamically unstable patients with pelvic ring disruption
}

Received: 17 January 2004 / Published online: 24 June 2005

(C) Springer-Verlag 2005

\begin{abstract}
Introduction Hemorrhage is the leading cause of death in patients with a pelvic fracture. The majority of blood loss derives from injured retroperitoneal veins and broad cancellous bone surfaces. The emergency management of multiply injured patients with pelvic ring disruption and severe hemorrhage remains controversial. Although it is well accepted that the displaced pelvic ring injury must be rapidly reduced and stabilized, the methods by which control of hemorrhagic shock is achieved remain under discussion. It has been proposed to exclusively use external pelvic ring stabilization for control of hemorrhage by producing a 'tamponade effect' of the pelvis. However, the frequency of clinically important arterial bleeding after external fixation of the pelvic ring remains unclear. We therefore undertook this retrospective review to attempt to answer this one important question: How frequently is arterial embolization necessary to control hemorrhage and restore hemodynamic stability after external pelvic ring fixation? Materials and methods We performed a retrospective review of 55 consecutive patients who presented with unstable types $\mathrm{B}$ and $\mathrm{C}$ pelvic ring fractures. Those patients designated as being in hemorrhagic shock (defined as a systolic blood pressure less than $90 \mathrm{mmHg}$ after receiving $2 \mathrm{~L}$ of intravenous crystalloid) were treated by application of the pelvic C-clamp. Patients who remained in hemorrhagic shock, or were determined to be in severe shock (defined as mandatory catecholamines or more than 12 blood transfusions over
\end{abstract}

No benefits in any form have been received or will be received from a commercial party related directly or indirectly to the subject of this article. No funds were received in support of this study.

H. Sadri · T. Nguyen-Tang · R. Stern $(\bowtie) \cdot$ P. Hoffmeyer

R. Peter

Orthopaedic Surgery Service,

University Hospital of Geneva,

24, rue Micheli-du-Crest

1211 Geneva 14, Switzerland

E-mail: richard.stern@hcuge.ch

Tel.: + 41-22-3727849

Fax: $+41-22-3727799$
$2 \mathrm{~h}$ ), underwent therapeutic angiography within $24 \mathrm{~h}$ in order to control bleeding. Results Fourteen patients were identified as being hemodynamically unstable (ISS $30.1 \pm 11.3$ points) and were treated with a C-clamp. In those patients with persistent hemodynamic instability, arterial embolization was performed. After C-clamp application, 5 of 14 patients required therapeutic angiography to control bleeding. Two patients died, one from multiple sources of bleeding and the other from an open pelvic fracture (total mortality 2/14, 14\%). Conclusions Although the C-clamp is effective in controlling hemorrhage, one must be aware of the need for arterial embolization to restore hemodynamic stability in a select subgroup of patients.

Keywords Pelvic fracture $\cdot$ Pelvic hemorrhage C-clamp $\cdot$ Pelvic angiography $\cdot$ Arterial embolization

\section{Introduction}

Hemorrhage associated with pelvic fractures presents a therapeutic challenge. While it is the leading cause of death (between $30 \%$ and $58 \%$ ) $[15,23,26]$ in patients with a pelvic fracture, it has been reported that among those who die, the pelvic fracture is the actual cause of death in less than $50 \%$ of cases [4]. The majority of blood loss is from injured retroperitoneal veins and bone, the latter accounted for by the broad cancellous surfaces at the fracture site. Only $20 \%$ of the deaths are associated with major arterial injury [3]. The search for the source of bleeding includes the thoracic cavity, intraperitoneal cavity, the retroperitoneal space, as well as the extremities.

The emergency management of multiply injured patients with pelvic ring disruption and severe hemorrhage remains controversial. Although it is well accepted that the displaced pelvic ring injury must be rapidly reduced and stabilized [10, 24], the methods by which control of hemorrhagic shock is achieved remain under 
discussion. It has been proposed to exclusively use external pelvic ring stabilization for control of hemorrhage by producing a 'tamponade effect' of the pelvis [11, $24]$, and this can be obtained with the C-clamp [10, 15]. Ertel et al. [9] have proposed pelvic packing when the C-clamp proves insufficient to control bleeding. It has been reported that $2-11 \%$ of all patients with unstable pelvic fractures require embolization due to persistent arterial bleeding $[1,2]$, and there are recommendations for vascular embolization to restore hemodynamic stability without the use of external pelvic fixation [1, 19, 20]. However, the frequency of clinically important arterial bleeding after external fixation of the pelvic ring remains unclear. We therefore undertook this retrospective review to attempt to answer this one important question: How frequently is arterial embolization necessary to control hemorrhage and restore hemodynamic stability after external pelvic ring fixation?

\section{Patients and methods}

From January 1, 1991, to December 31, 1999, 55 consecutive patients with unstable pelvic fractures classified as subgroups of types $\mathrm{B}$ and $\mathrm{C}$ injuries according to Tile and Pennal [28] were admitted to our level I hospital for surgical management. Thirty-five patients were classified as polytrauma, defined as having at least 2 different injuries with one of these being life-threatening [7], and an Injury Severity Score (ISS) equal to or greater than 20 points [13]. The evaluation of the patient and resuscitation protocol were performed according to ATLS guidelines [5]. All patients underwent ultrasound of the abdomen as part of our standard protocol. Further assessment included plain radiographs of the chest, pelvis, cervical and thoracolumbar spine.

Fourteen of these patients had hemorrhagic shock, defined as a systolic blood pressure less than $90 \mathrm{mmHg}$ after receiving $2 \mathrm{~L}$ of intravenous crystalloid $[1,2]$. In these patients, the pelvic ring was reduced and main- tained by external fixation using a pelvic anti-shock C-clamp within $2 \mathrm{~h}$ of arrival at our hospital. In all patients, the C-clamp was positioned according to the method of Ganz et al. [10] with the use of the image intensifier, providing anteroposterior, inlet and outlet views. In patients with a diastasis of the pubic symphysis, C-clamp application reduced this to less than $1 \mathrm{~cm}$. In those patients with vertical and/or posterior displacement of the hemipelvis, C-clamp application was preceded by traction on the involved side lower extremity which was successful in achieving a satisfactory reduction within $1 \mathrm{~cm}$ of displacement. Patients who remained in hemorrhagic shock, or were determined to be in severe shock (defined as mandatory catecholamines or more than 12 blood transfusions over $2 \mathrm{~h} \mathrm{[17]),} \mathrm{underwent} \mathrm{therapeutic}$ angiography within $24 \mathrm{~h}$ in order to control bleeding. Our protocol did not change during the period of evaluation during this retrospective study. Patients were followed for a minimum of 2 weeks after admission to the hospital. These patients were out of the intensive care unit and either on the general orthopaedic ward or had been transferred to a rehabilitation facility.

\section{Statistical analysis}

Statistical analysis was made using SPSS software, version 8.0.1 (SPSS, Chicago, IL, USA). Descriptive statistics were used, and ISS scores are presented as mean and standard deviation. Wilcox signed rank test was used to compare the data before and after C-clamp application. The $p$-value reported is two-sided. The results were considered statistically signficant if $p<0.05$.

\section{Results}

The average age of the 55 patients was 36 years (range 16-66 years). There were 42 men and 13 women. The mechanisms of injury included motorcycle accidents

Table 1 Details of patients treated with C-clamp (ISS Injury Severity Score)

\begin{tabular}{|c|c|c|c|c|c|}
\hline Patient number & Age & ISS & Fracture type & Associated injuries & Death (time) \\
\hline $1^{\mathrm{a}}$ & 37 & 20 & $\mathrm{C} 1$ & Multiple fractures of extremities, soft tissues & - \\
\hline 2 & 34 & 25 & B1 (open) & Head, extremity fracture, soft tissues & - \\
\hline 3 & 48 & 20 & $\mathrm{C} 1$ & Head, multiple fractures of extremities & - \\
\hline $4^{\mathrm{a}}$ & 63 & 25 & $\mathrm{C} 1$ & Head, severe soft tissues & - \\
\hline $5^{b}$ & 24 & 36 & C3 (open) & Head, rectum, spine, multiple fractures of extremities & 4 weeks \\
\hline 6 & 27 & 20 & $\mathrm{C} 1$ & Head, extremity fracture & - \\
\hline 7 & 46 & 25 & $\mathrm{C} 1$ & Bladder, multiple fractures of extremities & - \\
\hline $8^{\mathrm{a}}$ & 56 & 25 & $\mathrm{~B} 1$ & Severe soft tissues & - \\
\hline 9 & 25 & 25 & B1 & Head, multiple fractures of the extremities, soft tissues & - \\
\hline 10 & 42 & 29 & $\mathrm{C} 1$ & Bladder, pancreas, multiple fractures of extremities & - \\
\hline 11 & 55 & 25 & $\mathrm{C} 1$ & Severe soft tissues & - \\
\hline $12^{\mathrm{a}}$ & 24 & 48 & $\mathrm{C} 2$ & Liver, pancreas, thoracic, bladder & - \\
\hline $13^{\mathrm{a}, \mathrm{b}}$ & 66 & 41 & $\mathrm{~B} 2$ & Liver, spleen, spine & $<12 \mathrm{~h}$ \\
\hline 14 & 20 & 57 & B1 & Head, liver, rectum, thoracic, extremity fracture & - \\
\hline
\end{tabular}

\footnotetext{
${ }^{a}$ Arterial embolization
}

${ }^{\mathrm{b}}$ Deceased 
Table 2 Details of blood units administered before and after C-clamp application

\begin{tabular}{lll}
\hline Patient & $\begin{array}{l}\text { Number of blood units } \\
\text { before C-clamp application }\end{array}$ & $\begin{array}{l}\text { Number of blood units } \\
\text { after C-clamp application }\end{array}$ \\
\hline 1 & 4 & 10 \\
2 & 8 & 9 \\
3 & 3 & 2 \\
4 & 5 & 10 \\
5 & 14 & 14 \\
6 & 3 & 2 \\
7 & 9 & 8 \\
8 & 4 & 6 \\
9 & 7 & 10 \\
10 & 10 & 7 \\
11 & 4 & 3 \\
12 & 7 & 11 \\
13 & 7 & 43 \\
14 & 15 & 9 \\
\hline
\end{tabular}

$(n=20)$, falls from a great height $(n=17)$, and motor vehicle accidents $(n=12)$. Other patients were injured as pedestrians $(n=3)$, in a tram $(n=1)$ or bicycle accident $(n=1)$, or following a crush injury $(n=1)$. Analysis of the pelvic fractures showed 25 type $\mathrm{B}$ fractures $(\mathrm{B} 1=16$; $\mathrm{B} 2=9)$ and 30 type $\mathrm{C}(\mathrm{C} 1=26, \mathrm{C} 2=2, \mathrm{C} 3=2)$. Motorcycle accidents were responsible for all the open fractures in this series ( 3 type B and 2 type $\mathrm{C}$ ). Associated injuries included: central nervous system $(n=16)$, chest $(n=10)$, urogenital $(n=13)$, spleen $(n=5)$, liver $(n=8)$, pancreas $(n=7)$, rectal $(n=3)$, sacral plexus $(n=8)$ and injuries of the extremities $(n=44)$.

Of these 55 consecutive patients, 14 with pelvic ring disruption and hemodynamic instability were treated with pelvic stabilization utilizing the C-clamp (Table 1). The mean ISS of the entire patient population was $25.2 \pm 7.1$ points. The mean ISS of this group of 14 patients was $30.1 \pm 11.3$ points. There were no C-clamprelated complications. These 14 patients received an average of 17 units of blood (range 6-50 units). Details concerning blood transfusions before and after C-clamp application are summarized in Table 2. Although the Cclamp was efficient in most cases in stabilizing the patients, the number of blood units transfused before and after C-clamp application was not statistically significant $(p=0.308)$.

Seven patients underwent angiography. Two patients were excluded from our evaluation of angiography in controlling acute hemorrhage. One was a patient who required angiography 28 days post-injury to control hemorrhage from the obturator artery after removal of a perineal drain which had been placed following drainage of a perineal abscess. An additional patient underwent angiography for evaluation of a cold lower extremity which was due to a dissection of the superficial femoral artery. In the remaining 5 patients, emergent arterial embolization within $24 \mathrm{~h}$ was required to control bleeding and restore hemodynamic stability. The characteristics of these patients, including time to embolization, length of time for the procedure, and transfusion before and after angiography, are summarized in Table 3. Therapeutic angiography was efficient in controlling bleeding in 4 out of 5 patients, but one patient (\#13) who had sustained liver and spleen injuries and a mesenteric artery injury died within $12 \mathrm{~h}$ after arrival from multifocal exsanguinating hemorrhage. He was the only patient to have undergone a laparotomy. Another patient with an open type $\mathrm{C}$ pelvic fracture who had been initially stabilized with a pelvic clamp and concomitant colostomy died 4 weeks after admission from septic shock. Global mortality overall was $7 \%(4 / 55)$, and among the patients treated with the C-clamp it was $14 \%$ (2/14 patients).

\section{Discussion}

Exsanguinating hemorrhage represents the major cause of death within the first $24 \mathrm{~h}$ after injury in multiply injured patients with pelvic ring fractures [12, 21, 25, 27]. An average blood loss of 9.2 to 14.8 units has been recorded in patients with unstable pelvic ring fractures [4], with Dalal et al. [6] noting lower blood loss and transfusion requirements in patients sustaining lateral compression injuries compared with other types. A 3\% mortality rate was reported in patients with normal hemodynamics, compared with a $38 \%$ mortality rate for those admitted in a hypotensive state [18]. For this reason, the immediate recognition of hemorrhagic shock and effective control of bleeding play a crucial role in patient survival.

The treatment of exsanguinating hemorrhage in multiply injured patients with pelvic ring disruption is controversial. Although acute reduction and external fixation of the disrupted pelvis are well accepted methods $[10,24]$, which specific technique and device to use

Table 3 Details of patients requiring arterial embolization for hemodynamic instability

\begin{tabular}{|c|c|c|c|c|c|c|}
\hline $\begin{array}{l}\text { Patient } \\
\text { number }\end{array}$ & $\begin{array}{l}\text { Time to } \\
\text { embolization } \\
\text { (h) }\end{array}$ & $\begin{array}{l}\text { Number of units } \\
\text { transfused before } \\
\text { embolization }\end{array}$ & $\begin{array}{l}\text { Number of units } \\
\text { transfused after } \\
\text { embolization }\end{array}$ & $\begin{array}{l}\text { Arteries } \\
\text { embolized }\end{array}$ & $\begin{array}{l}\text { Reason for } \\
\text { angiography }\end{array}$ & $\begin{array}{l}\text { Death } \\
\text { (time) }\end{array}$ \\
\hline 1 & 18 & 14 & 0 & Obturator & Hemorrhagic shock & - \\
\hline 4 & 12 & 15 & 0 & Lateral sacral & Hemorrhagic shock & - \\
\hline 8 & 1 & 9 & 1 & Superior gluteal & Severe shock & - \\
\hline 12 & 2 & 16 & 2 & Small branch of external iliac & Severe shock & - \\
\hline $13^{\mathrm{b}}$ & 3 & 10 & 40 & Superior gluteal; bilateral lumbar L3 & Hemorrhagic shock & $<12 \mathrm{~h}$ \\
\hline
\end{tabular}

\footnotetext{
${ }^{\mathrm{b}}$ Deceased
} 
give rise to debate. Although we have not used this in the emergency setting, ORIF, such as bridge plating of the symphysis pubis of open book lesions, may also be useful in diminishing pelvic volume and thus controlling hemorrhage. Because of the critical hemodynamic condition of these patients, we favor only external devices that are easily applicable and can be used effectively. We prefer the C-clamp because of its mechanical superiority over an anterior frame, particularly in cases of type $\mathrm{C}$ injuries [22]. Although an anterior external fixator provides sufficient stability in type B1 pelvic ring injuries (open book), the anteroposterior view of the pelvis obtained in the emergency room often does not permit one to distinguish it from a type C injury. In this study, hemodynamically unstable patients were rapidly transferred to the operating room, where the C-clamp was assembled and applied within $20 \mathrm{~min}$ in all patients, thus achieving adequate stability of the pelvic ring quickly. This review, similar to others $[9,10,15,23,26,29]$, confirms the effectiveness of the C-clamp in the emergency situation in controlling the pelvic ring in patients with severe hemorrhage.

Control of retroperitoneal bleeding may be achieved in three ways, namely by: (1) decreasing blood loss from broad cancellous surfaces at fracture sites and lacerated veins and soft tissues by stabilizing the fracture and the forming hematoma; (2) limiting low pressure bleeding by normalization of pelvic volume and a retroperitoneal tamponade effect; and (3) localizing and controlling arterial bleeding sites via therapeutic angiography or surgical exploration. External pelvic fixation is effective in controlling hemorrhage by the first two mechanisms cited $[11,16,24]$, while a recent study suggests that although low-pressure venous hemorrhage may be tamponaded by an external fixator, it is unlikely that such a fixator can generate sufficient pressure to stop arterial bleeding [14]. In a recent study, Ertel [9] questioned the efficiency of external fixation in controlling retroperitoneal hemorrhage by the tamponade effect. Based on intraoperative findings, he pointed out that the retroperitoneal hematoma can drain not only through the ruptured pelvic floor, but also into the abdomen or chest, and thus one does not achieve a tamponade effect. Therefore, laparotomy and pelvic packing were recommended. The mortality in this group of patients was $25 \% \quad(5 / 20$ patients). Although exploration of the hematoma, ligation of obvious bleeding sites, and packing of the retroperitoneal space have been largely abandoned in North America, such an approach has its ardent supporters [8, 9, 23].

Angiography with embolization has been described as an alternative for controlling pelvic fracture hemorrhage $[1,2,19,20]$. Agolini et al. [1, 2, 19, 20] reported that only $1.9 \%$ of patients ( $15 / 806$ patients) with pelvic ring injury required embolization. Although the authors could successfully stop bleeding in all patients, the mortality was $47 \%$. Our experience in type B and C fractures revealed 14 of 55 patients $(26 \%)$ to be hemodynamically unstable, requiring C-clamp pelvic stabilization. In 9 patients, no further treatment was required to maintain hemodynamic stability. But in 5 patients $(9 \%)$, therapeutic angiography was necessary to control bleeding. The most frequent artery requiring embolization was the superior gluteal (3 out of 7 vessels), and this vessel seems to be more frequently injured in posterior pelvic fractures [19]. Similar results have been reported by Burgess et al., where 11 of 162 patients $(7 \%)$ required angiography, but this number increased to $20 \%$ of the total in those with unstable fracture patterns [4]. In our study, four B1 lesions were treated with the C-clamp (patients 2, 8, 9, and 14). The C-clamp was effective in stabilizing three of these patients, but one patient required embolization (patient 4). The C-clamp seems efficient in controlling hemorrage in this type of lesion, although our numbers are too small to achieve statistical significance. Only one patient with a B2 lesion was treated with the clamp and embolization, but unfortunately died. We cannot therefore draw conclusions about the usefulness of the C-clamp in this lesion pattern.

In a report of 20 patients treated with the C-clamp [9], $14(70 \%)$ underwent pelvic packing to control bleeding. The global mortality rate was $25 \%$, and the mortality rate of patients who required both a C-clamp and pelvic packing was $29 \%$ (4/14 patients). In our study, the global mortality rate in a similar group of patients was $14 \%$ (2/14 patients), and in the subgroup who needed embolization, it was $20 \%$ ( $1 / 5$ patients). However, the number of patients in both of these studies is small and does not permit statistical analysis. Nevertheless, it is clear that in some patients external fixation by itself for unstable pelvic ring disruptions is not sufficient for effective control of bleeding. The C-clamp and adjunctive embolization appears to be as efficient in controlling hemorrhage as the C-clamp associated with laparotomy and pelvic packing. In those hospitals where angiography facilities are available, it seems reasonable to recommend that patients who remain hemodynamically unstable after rapid application of the C-clamp be treated with arterial embolization. Although the C-clamp was effective in controlling hemorrhage in the majority of patients in this review, $36 \%$ required arterial embolization to control hemorrhage.

\section{References}

1. Agolini SF, Shah K, Jaffe J, Newcomb J, Rhodes M, Reed JF, 3rd (1997) Arterial embolization is a rapid and effective technique for controlling pelvic fracture hemorrhage. J Trauma 43:395-399

2. Ben-Menachem Y, Coldwell DM, Young JW, Burgess AR (1991) Hemorrhage associated with pelvic fractures: causes, diagnosis, and emergent management. Am J Roentgenol 157:1005-1014

3. Brown JJ, Greene FL, McMillin RD (1984) Vascular injuries associated with pelvic fractures. Am Surg 50:150-154

4. Burgess AR, Eastridge BJ, Young JW, Ellison TS, Ellison PS, Jr., Poka A, Bathon GH, Brumback RJ (1990) Pelvic ring disruptions: effective classification system and treatment protocols. J Trauma 30:848-856 
5. Collicott PE, Hughes I (1980) Training in advanced trauma life support. Jama 243:1156-1159

6. Dalal SA, Burgess AR, Siegel JH, Young JW, Brumback RJ, Poka A, Dunham CM, Gens D, Bathon H (1989) Pelvic fracture in multiple trauma: classification by mechanism is key to pattern of organ injury, resuscitative requirements, and outcome. J Trauma 29:981-1000; discussion 1000-1002

7. Ertel W, Friedl HP, Trentz O (1994) Multiple organ dysfunction syndrome (MODS) following multiple trauma: rationale and concept of therapeutic approach. Eur J Pediatr Surg 4:243248

8. Ertel W, Oberholzer A, Platz A, Stocker R, Trentz O (2000) Incidence and clinical pattern of the abdominal compartment syndrome after 'damage-control' laparotomy in 311 patients with severe abdominal and/or pelvic trauma. Crit Care Med 28:1747-1753

9. Ertel W, Keel M, Eid K, Platz A, Trentz O (2001) Control of severe hemorrhage using C-clamp and pelvic packing in multiply injured patients with pelvic ring disruption. J Orthop Trauma 15:468-474

10. Ganz R, Krushell RJ, Jakob RP, Kuffer J (1991) The antishock pelvic clamp. Clin Orthop 267:71-78

11. Ghanayem AJ, Wilber JH, Lieberman JM, Motta AO (1995) The effect of laparotomy and external fixator stabilization on pelvic volume in an unstable pelvic injury. J Trauma 38:396400

12. Gilliland MD, Ward RE, Barton RM, Miller PW, Duke JH (1982) Factors affecting mortality in pelvic fractures. J Trauma 22:691-693

13. Greenspan L, McLellan BA, Greig H (1985) Abbreviated Injury Scale and Injury Severity Score: a scoring chart. J Trauma 25:60-64

14. Grimm MR, Vrahas MS, Thomas KA (1998) Pressure-volume characteristics of the intact and disrupted pelvic retroperitoneum. J Trauma 44:454-459

15. Heini PF, Witt J, Ganz R (1996) The pelvic C-clamp for the emergency treatment of unstable pelvic ring injuries. A report on clinical experience of 30 cases. Injury 27:S-A38-45

16. Kellam JF (1989) The role of external fixation in pelvic disruptions. Clin Orthop 241:66-82
17. McMurtry R, Walton D, Dickinson D, Kellam J, Tile M (1980) Pelvic disruption in the polytraumatized patient: a management protocol. Clin Orthop 151:22-30

18. Naam NH, Brown WH, Hurd R, Burdge RE, Kaminski DL (1983) Major pelvic fractures. Arch Surg 118:610-616

19. O’Neill PA, Riina J, Sclafani S, Tornetta P 3rd (1996) Angiographic findings in pelvic fractures. Clin Orthop 329:60-67

20. Panetta T, Sclafani SJ, Goldstein AS, Phillips TF, Shaftan GW (1985) Percutaneous transcatheter embolization for massive bleeding from pelvic fractures. J Trauma 25:1021-1029

21. Patterson FP, Morton KS (1973) The cause of death in fractures of the pelvis: with a note on treatment by ligation of the hypogastric (internal iliac) artery. J Trauma 13:849-856

22. Pohlemann T, Krettek C, Hoffmann R, Culemann U, Gansslen A (1994) Biomechanical comparison of various emergency stabilization measures of the pelvic ring (in German). Unfallchirurg 97:503-510

23. Pohlemann T, Culemann U, Gansslen A, Tscherne H (1996) Severe pelvic injury with pelvic mass hemorrhage: determining severity of hemorrhage and clinical experience with emergency stabilization. Unfallchirurg 99:734-743

24. Riemer BL, Butterfield SL, Diamond DL, Young JC, Raves JJ, Cottington E, Kislan K (1993) Acute mortality associated with injuries to the pelvic ring: the role of early patient mobilization and external fixation. J Trauma 35:671-675; discussion 676-677

25. Rothenberger DA, Fischer RP, Strate RG, Velasco R, Perry JF Jr (1978) The mortality associated with pelvic fractures. Surgery $84: 356-361$

26. Schutz M, Stockle U, Hoffmann R, Sudkamp N, Haas N (1996) Clinical experience with two types of pelvic C-clamps for unstable pelvic ring injuries. Injury 27:S-A46-50

27. Sevitt S (1968) Fatal road accidents. Injuries, complications, and causes of death in 250 subjects. Br J Surg 55:481-505

28. Tile M, Pennal GF (1980) Pelvic disruption: principles of management. Clin Orthop 151:56-64

29. Witschger P, Heini P, Ganz R (1992) Pelvic clamps for controlling shock in posterior pelvic ring injuries. Application, biomechanical aspects and initial clinical results. Orthopade 21:393-399 